\title{
Efficacy of a modified regimen of gemcitabine and cisplatin among women with recurrent epithelial ovarian cancer
}

\author{
Gamal H. Eltabbakh, Erin Donovan, Georgia Eltabbakh \\ Lake Champlain Gynecologic Oncology, P.C., South Burlington, Vermont, USA
}

Received: Feburay 7, 2016

Accepted: March 20, 2016

Online Published: March 23, 2016

DOI: $10.5430 /$ jst.v6n2p1

URL: http://dx.doi.org/10.5430/jst.v6n2p1

\begin{abstract}
Objective: To assess the efficacy, side effects and progression-free interval of a modified regimen of the combination of gemcitabine and cisplatin among women with recurrent epithelial ovarian cancer.

Methods: Twenty-eight women with recurrent epithelial ovarian, primary peritoneal or fallopian tube cancers were treated with gemcitabine $\left(500 \mathrm{mg} / \mathrm{m}^{2}\right)$ followed by cisplatin $\left(50 \mathrm{mg} / \mathrm{m}^{2}\right)$ on days one and eight every three weeks. Patients' demographics, response, side effects, and progression-free interval were recorded.

Result: The median age of patients was 61 (range 44-74 years). Twenty-three (82.1\%) patients had platinum-sensitive and five $(17.9 \%)$ had platinum-resistant tumors. The median number of prior chemotherapy regimens was two (range 1-4) and nine patients had $>$ three prior regimens. The median number of cycles was six (range 2-10). Seventeen (60.7\%) patients responded to chemotherapy (11 complete and six partial), six had stable disease and five had progression. The response rate was $69.6 \%$ and 20\% among women with platinum-sensitive and platinum-resistant tumors, respectively ( $P=.024)$. The median (range) progression-free interval was six (2-12) and nine (4-12) months among all patients and patients who responded to chemotherapy, respectively. Four patients had dose reductions, four had delays and three had their chemotherapy terminated secondary to toxicity or patient desire. There were no chemotherapy-related mortality or hospital admissions. The incidence of grade 3-4 neutropenia, anemia, thrombocytopenia, and nausea or vomiting was $32.1 \%, 10.7 \%, 35.7 \%$, and $10.7 \%$, respectively.

Conclusion: The combination gemcitabine and cisplatin is highly effective among women with recurrent ovarian cancer including those who are heavily pre-treated and is reasonably tolerated. Although, the combination is effective among women with plantinum-resistant tumors, these women have a lower response than women with platinum-sensitive tumors.
\end{abstract}

Key Words: Recurrent ovarian cancer, Chemotherapy, Gemcitabine, Cisplatin

\section{INTRODUCTION}

Approximately $65 \%$ of all patients diagnosed with ovarian cancer have recurrence or persistent disease. Treatment of women with recurrent ovarian cancer usually entails systemic chemotherapy with or without cytoreductive surgery. Women with recurrent ovarian cancer usually develop new recurrences following treatment and often undergo multiple lines of chemotherapy. Treatment of recurrent ovarian cancer is challenging as no single chemotherapy regimen is clearly superior to the others although recent studies ${ }^{[1,2]}$ have demonstrated an advantage to combination as compared to single agent chemotherapy.

\footnotetext{
*Correspondence: Gamal H. Eltabbakh, MD; Email: geltabbakh@lcgo.com; Address: Lake Champlain Gynecologic Oncology, 1060 Hinesburg Road, South Burlington, Vermont, USA.
} 
Prognosis of women with recurrent ovarian cancer is dependent on the length of progression-free interval (PFI) and their response to platinum-based therapy. These women have been customarily divided into platinum-resistant and platinumsensitive depending on the time interval between initial treatment and tumor recurrence (less than or more than 6 months, respectively). Women with recurrent platinum-sensitive ovarian cancer have been treated with platinum-based chemotherapy ${ }^{[3,4]}$ and those with platinum-resistant tumors have been treated with Taxol, Doxil and topotecan. ${ }^{[5-7]}$

Over the last several decades, cisplatin has been one of the most active and commonly employed agents in ovarian cancer. Cisplatin acts by formation of various platinum DNA adducts that form covalent bonds with DNA. Platinum resistance may be due in part to increased DNA repair activity (secondary to loss of mismatch repair genes). ${ }^{[8]}$

Gemcitabine is a pyridamine antimetabolite which blocks DNA replication (repair) and inhibits DNA synthesis. Gemcitabine has been found to be active in women with primary ${ }^{[9]}$ and recurrent ${ }^{[10]}$ ovarian cancer. The addition of gemcitabine to cisplatin may have synergistic tumoricidal activity even in women with platinum-resistant tumors. It is postulated that gemcitabine prevents DNA synthesis and repair and thus helps circumvent platinum resistance ${ }^{[11,12]}$ Several studies have evaluated the combination gemcitabine and cisplatin (or carboplatin) among women with primary ${ }^{[13,14]}$ and recurrent $^{[2,15-22]}$ ovarian cancer.

Different regimens of the combination of gemcitabine and cisplatin have been used by different authors among women with recurrent ovarian cancer. Villella and co-workers ${ }^{[16]}$ applied gemcitabine $\left(1,000 \mathrm{mg} / \mathrm{m}^{2}\right)$ and cisplatin $\left(75 \mathrm{mg} / \mathrm{m}^{2}\right)$ on day 1 and gemcitabine $\left(1,000 \mathrm{mg} / \mathrm{m}^{2}\right)$ only on day 8 every 21 days. One of the common problems with this regimen has been severe myelotoxicity following day 1 precluding the administration of chemotherapy on day 8 among a large percentage of the patients. Nagourney et al. ${ }^{[17]}$ used cisplatin $\left(30 \mathrm{mg} / \mathrm{m}^{2}\right)$ followed by gemcitabine $\left(750 \mathrm{mg} / \mathrm{m}^{2}\right)$ on days 1,8 and 15 every 28 days. The latter regimen was later modified to days 1 and 8 every 21 days and the gemcitabine dose was reduced to $600 \mathrm{mg} / \mathrm{m}^{2}$ among women with 2 or more prior chemotherapy regimens. Rose and colleagues ${ }^{[15]}$ used gemcitabine $\left(750 \mathrm{mg} / \mathrm{m}^{2}\right)$ on day 1 followed by cisplatin $\left(30 \mathrm{mg} / \mathrm{m}^{2}\right)$ on days 1 and 8 every 21 days. In a schedule finding study involving the combination gemcitabine and cisplatin, Kroep et al. ${ }^{[23]}$ found that myelotoxicity was the most important toxicity and that leukopenia was schedule dependent: gemcitabine before cisplatin was less toxic than the reversed sequence.

In 2002, we started using a modified gemcitabine and cis- platin regimen among patients with recurrent ovarian cancer with the aim of reducing myelotoxicity and avoiding drug omissions or delays. The objective of the current study was to assess the efficacy, side effects and PFI of the combination gemcitabine $\left(500 \mathrm{mg} / \mathrm{m}^{2}\right)$ followed by cisplatin $\left(50 \mathrm{mg} / \mathrm{m}^{2}\right)$ given on days 1 and 8 every 21 days among women with recurrent ovarian cancer.

\section{Patients and methods}

The study is a retrospective review of our experience with the combination gemcitabine and cisplatin among women with recurrent epithelial ovarian, primary peritoneal or fallopian tube cancers who received taxane and platinum combination chemotherapy as first-line treatment. Our chemotherapy data base at Lake Champlain Gynecologic Oncology, PC was reviewed and patients with recurrent epithelial ovarian, primary peritoneal or fallopian tube cancers treated with the combination gemcitabine and cisplatin were identified. All Patients signed an informed consent before the start of chemotherapy.

Inclusion criteria were:

(1) Histologically confirmed epithelial ovarian, primary peritoneal or fallopian tube cancer.

(2) Patients were treated with taxane and platinum systemic chemotherapy at time of initial diagnosis.

(3) Disease recurrence documented by computed tomography, surgery at second look operation or secondary cytoreduction, or elevation of CA-125 to $>100 \mathrm{U} / \mathrm{ml}$.

(4) Performance status of 0-2 [Gynecologic Oncology Group (GOG)].

(5) Normal serum creatinine and liver function tests.

(6) Adequate bone marrow with absolute neutrophilic count $>1,000$ and platelet count $>100,000$.

(7) No prior allergic reactions to cisplatin or gemcitabine.

Performance status was reported based on the GOG scale and the toxicities were recorded based on the common toxicity criteria. Platinum-sensitivity was defined as tumor recurrence more than six months following the end of first-line chemotherapy. Platinum-resistance was defined as persistent disease, tumor recurrence or progression less than six months from the end of first-line chemotherapy.

Patients were given gemcitabine $\left(500 \mathrm{mg} / \mathrm{m}^{2}\right)$ followed by cisplatin $\left(50 \mathrm{mg} / \mathrm{m}^{2}\right)$ on days one and eight every 21 days with the usual pre and post-chemotherapy antinausea medications and hydration in the office. The intent was to deliver six cycles to each patient. Treatment was discontinued prior to six cycles among patients who showed tumor progression, severe toxicity or desired to stop treatment. Growth factor support was used according to American Society of Clinical Oncologists guidelines. 
Patients' demographics, response, side effects, and PFI following the combination gemcitabine and cisplatin were recorded. Patients were followed to assess their overall survival.

Response to treatment was assessed by computed tomography and CA-125 measurement. Response to treatment was classified as complete response, partial response, stable disease and progression using the WHO criteria ${ }^{[24]}$ among women with measurable disease. Among women with nonmeasurable but evaluable disease, response to treatment was based on CA-125 values using Rustin's criteria. ${ }^{[25]}$ Overall response was calculated by adding partial and complete responses. The difference in response rates between women with platinum-sensitive and those with platinum-resistant tumors was calculated using the chi square test with $P<.05$ as significant.

Table 1. Characteristics of patients $(n=28)$ included in the study at time of diagnosis

\begin{tabular}{ll}
\hline & Number (\%) \\
\hline Tumor & $22(78.6 \%)$ \\
Epithelial ovarian cancer & $4(14.3 \%)$ \\
Primary peritoneal cancer & $2(7.1 \%)$ \\
Fallopian tube cancer & \\
Histology & $24(85.7 \%)$ \\
Papillary serous & $3(10.7 \%)$ \\
Clear cell & $1(3.6 \%)$ \\
Undifferentiated & \\
Tumor grade & $1(3.6 \%)$ \\
Grade 1 & $6(21.4 \%)$ \\
Grade 2 & $21(75 \%)$ \\
Grade 3 & \\
Stage at diagnosis & $2(7.1 \%)$ \\
Stage 1 & $1(3.6 \%)$ \\
Stage 2 & $19(67.9 \%)$ \\
Stage 3 & $6(21.4 \%)$ \\
Stage 4 & \\
Primary cytoreduction & $22(78.6 \%)$ \\
Optimal & $6(21.4 \%)$ \\
Suboptimal & \\
First-line chemotherapy & $23(82.1 \%)$ \\
Taxol/Carboplatin & $(10.7 \%)$ \\
Taxol/Cisplatin & \\
Taxotere/Carboplatin & \\
\hline & \\
\hline
\end{tabular}

\section{RESUlts}

Twenty eight patients with recurrent epithelial ovarian, primary peritoneal or fallopian tube cancers treated between July 2002 and December 2006 constituted the study population. The median (range) age of patients was 61 years (44-74). Table 1 lists patients' characteristics at the time of their original diagnosis. Twenty-three $(82.1 \%)$ patients had platinum- sensitive and five (17.9\%) had platinum-resistant tumors. The median number of prior chemotherapy regimens was two (range 1-4) and nine (32.1\%) patients had $>$ three prior regimens. Most patients had papillary serous histology (86\%) and grade 3 tumors (75\%).

All patients received platinum and taxanes as first-line chemotherapy. The median (range) duration between firstline chemotherapy and recurrence among platinum-sensitive patients $(n=23)$ was $18(6-60)$ months. Prior to gemcitabine/cisplatin chemotherapy, six patients underwent secondary cytoreductive surgery. Of the 28 patients included in the study, 22 had measurable and six patients had nonmeasurable but evaluable disease. The performance status of the patients was 0 , one and two in 21 , six and one patients, respectively.

The median number of gemcitabine/ cisplatin cycles was six (range 2-10). Seventeen (60.7\%) patients responded to chemotherapy (11 complete and 6 partial), six had stable disease and five had progression. The response rates were 69.6\% among the 23 patients with platinum-sensitive tumors (47.8\% complete and $21.7 \%$ partial) and $20 \%$ among the five patients with platinum-resistant disease. The difference between the two response rates was statistically significant $(P=$ .024). The only patient with platinum-resistant disease who responded to chemotherapy had a partial response. Another patient with platinum-resistant disease had stable disease. None of the patients were lost to follow-up. The median (range) PFI following gemcitabine and cisplatin was six (212 months) months for all patients. The median (range) PFI for patients who responded to gemcitabine and cisplatin was nine (4-12) months. Patients with platinum-sensitive tumors had a longer median PFI compared with those with platinumresistant tumors (seven $v s$. four months). At the time of last follow-up, six patients were alive without disease, 14 patients were alive with disease, six patients were deceased from disease and two patients were deceased due to other causes.

Toxicities ascribable to chemotherapy are listed in Table 2 . Four patients had dose reductions, four had chemotherapy delays and three had their chemotherapy terminated secondary to myelotoxicity $(n=2)$ or patient's desire $(n=1)$. There were no chemotherapy-related mortality or hospital admissions for chemotherapy-related complications. The incidence of grade 3-4 neutropenia, anemia, thrombocytopenia, and nausea or vomiting were $32.1 \%, 10.7 \%, 35.7 \%$, and $10.7 \%$, respectively. Three (10.7\%) patients had grade 2 peripheral neuropathy and one $(3.5 \%)$ patient had tinnitus. Growth Factor support was used in 17 (60.7\%) patients. 
Table 2. Number (\%) of patients who demonstrated chemotherapy-related toxicities

\begin{tabular}{lllll}
\hline & Grade 1 & Grade 2 & Grade 3 & Grade 4 \\
\hline Neutropenia & $8(28.6 \%)$ & $5(17.9 \%)$ & $5(17.9 \%)$ & $4(14.3 \%)$ \\
Anemia & $1139.3 \%)$ & $4(14.3 \%)$ & $2(7.1 \%)$ & $1(3.6 \%)$ \\
Thrombocytopenia & $10(35.7 \%)$ & $6(21.4 \%)$ & $5(17.9 \%)$ & $5(17.9 \%)$ \\
Nausea or vomiting & $3(10.7 \%)$ & $2(7.1 \%)$ & $2(7.1 \%)$ & $1(3.6 \%)$ \\
Renal & $3(10.7 \%)$ & $2(7.1 \%)$ & 0 & 0 \\
Peripheral neuropathy & $15(53.6 \%)$ & $3(10.7 \%)$ & 0 & 0 \\
Fatigue & $16(57.1 \%)$ & $4(14.3 \%)$ & 0 & 0 \\
\hline
\end{tabular}

\section{Discussion}

The last decade has witnessed a prolongation of survival of women with ovarian cancer. ${ }^{[26]}$ As the majority of women with ovarian cancer have recurrences, it is expected that the number of women with recurrent ovarian cancer receiving chemotherapy as well as the number of chemotherapy regimens that these women might receive will increase. Several agents have been found effective among women with recurrent ovarian cancer. However, none of these agents produce a durable remission. Gynecologic and medical oncologists involved in the treatment of women with recurrent ovarian cancer face a major challenge in finding effective chemotherapy regimens that have reasonable toxicities and allow the patients to be fully functional and with acceptable quality of life.

The efficacy of gemcitabine and cisplatin among women with recurrent ovarian cancer has been demonstrated both as sin- gle agents and in combination. Several regimens of that combination have been reported by various authors. ${ }^{[2,15-22,29-31]}$ The modified regimen we started in 2002 which entailed reducing the dose of gemcitabine and increasing the total dose of cisplatin and dividing treatment over two weeks was adopted in the hope of maximizing efficacy and reducing myelotoxicity. In addition, we used growth factor support for both white and red blood cells in lieu of reducing chemotherapy doses and in order to avoid chemotherapy delays. Approximately $61 \%$ of our patients received growth factor support to treat or prevent neutropenia and anemia. None of our patients had febrile neutropenia. However, thrombocytopenia continued to be a major problem occurring in 26 $(92.9 \%)$ out of 28 patients. Grade 3 and 4 thrombocytopenia was the most frequent major complication occurring in $35.7 \%$ of our patients. Two patients in our study population had their chemotherapy terminated because of persistent thrombocytopenia.

Table 3. Studies of the combination gemcitabine and platinum among women with recurrent ovarian cancer

\begin{tabular}{|c|c|c|c|c|}
\hline Regimen author & Number of patients & Patients with platinum resistance & Response rate & PFI (months) \\
\hline \multicolumn{5}{|l|}{ Gemcitabine/cisplatin } \\
\hline Nagourney et al. ${ }^{[17]}$ & 27 & $52 \%$ & $70 \%$ & 6 \\
\hline Tewari et al. ${ }^{[19]}$ & 22 & $100 \%$ & $64 \%$ & 3.9 \\
\hline Brewer et al. ${ }^{[21]}$ & 57 & $100 \%$ & $16 \%$ & 5.9 \\
\hline Bozas et al. ${ }^{[29]}$ & 50 & $100 \%$ & $31.5 \%$ & 4 \\
\hline Current study & 28 & $18 \%$ & $60.7 \%$ & 7 \\
\hline \multicolumn{5}{|c|}{ Gemcitabine/carboplatin } \\
\hline Papadimitriou et al. ${ }^{[18]}$ & 43 & 0 & $40.4 \%$ & 9 \\
\hline Pfisterer et al. ${ }^{[2]}$ & 178 & 0 & $47.2 \%$ & 8.6 \\
\hline Kose et al. ${ }^{[20]}$ & 40 & 0 & $62.5 \%$ & $9.6^{*}$ \\
\hline Sufliarsky et al. ${ }^{[30]}$ & 53 & 0 & $67.3 \%$ & Not mentioned \\
\hline \multicolumn{5}{|c|}{ Gemcitabine/cisplatin or carboplatin } \\
\hline Rose et al. ${ }^{[15]}$ & 36 & $100 \%$ & $42.9 \%$ & 6 \\
\hline Villella et al. ${ }^{[16]}$ & 29 & $66 \%$ & $55 \%$ & $<6$ \\
\hline \multicolumn{5}{|c|}{ Gemcitabine/cisplatin or carbopltin and bevacizumab } \\
\hline Richardson et al. ${ }^{[31]}$ & 35 & $20 \%$ & $78 \%$ & 12 \\
\hline
\end{tabular}

Note. PFI: Progression-free interval for all patients included in the study. ${ }^{*}$ PFI was calculated for patients who responded to chemotherapy. Response rate means overall response and combines both partial and complete responses. 
Tables 3 and 4 compare the findings of our study with published reports on gemcitabine and platinum among women with recurrent ovarian cancer. The response rate, the PFI, the major toxicities and the rate of dose delays or omissions of chemotherapy among our patients compare favorably to those reported in other studies. ${ }^{[2,15-21]}$ In particular, only $25 \%$ of our patients had dose reductions or omissions compared to $31.8 \%-74.1 \%$ reported in other studies. ${ }^{[2,15-17,20]}$ We believe that this difference is secondary to the modified doses we used in our patients. Compared to cisplatin, gemcitabine produces more frequent myelotoxicity. This is likely to be more significant among heavily pre-treated women with recurrent ovarian cancer who have depleted bone marrow reserves from previous treatments. We were unable to correlate response of patients to their histologic tumor types as most of the patients in our study (86\%) had papillary serous histology.

Table 4. Grade 3 and 4 toxicities and dose reductions or omissions of the combination gemcitabine and platinum among women with recurrent ovarian cancer

\begin{tabular}{llllll}
\hline Author & Neutropenia & Anemia & Thrombocytopenia & Nausea/vomiting & Dose reduction or omission \\
\hline Rose et al. ${ }^{[15]}$ & $36 \%$ & $8.3 \%$ & $19.4 \%$ & $8.3 \%$ & $52.7 \%$ \\
Nagourney et al. ${ }^{[17]}$ & $81.5 \%$ & $18.5 \%$ & $96.3 \%$ & $14.8 \%$ & $74.1 \%$ \\
Villella et al. ${ }^{[16]}$ & $20.7 \%$ & $10.3 \%$ & $41.7 \%$ & $27.6 \%$ & $72 \%$ \\
Papadimitriou et al. ${ }^{[18]}$ & $69 \%$ & $26 \%$ & $31 \%$ & $21 \%$ & not mentioned \\
Pfisterer et al. ${ }^{[2]}$ & $70.3 \%$ & $27.4 \%$ & $34.9 \%$ & $2.9 \%$ & $52.7 \%$ \\
Kose et al. ${ }^{[2]}$ & $77.5 \%$ & $15 \%$ & $17.5 \%$ & $5 \%$ & $31.8 \%$ \\
Brewer et al. ${ }^{[21]}$ & $66.7 \%$ & $19.3 \%$ & $59.6 \%$ & $12.3 \%$ & not mentioned \\
Bozas et al. ${ }^{[29]}$ & $81.5 \%$ & $18.5 \%$ & $96.5 \%$ & $14.8 \%$ & not mentioned \\
Sufliarsky et al. ${ }^{[30]}$ & $22.7 \%$ & $20.8 \%$ & $28.4 \%$ & $5.7 \%$ & $60.3 \%$ \\
Richardson et al. ${ }^{[31]}$ & $29 \%$ & $11 \%$ & $14 \%$ & $9 \%$ & $54 \%$ \\
Current study & $32.1 \%$ & $10.7 \%$ & $35.7 \%$ & $10.7 \%$ & $25 \%$ \\
\hline
\end{tabular}

Note. ${ }^{*} 4 \%$ discontinued treatment for toxicity.

The combination gemcitabine and carboplatin is a reasonable alternative to the combination gemcitabine and cisplatin. A prospective randomized study compared the combination of gemcitabine and carboplatin to single agent carboplatin among women with recurrent platinum-sensitive ovarian cancer. ${ }^{[2]}$ These authors demonstrated that the combination regimen significantly improved the PFI and response rate without worsening the quality of life of patients. ${ }^{[2]}$ Compared to gemcitabine and cisplatin, the combination gemcitabine and carboplatin is expected to be associated with less nausea, vomiting and renal toxicity. Furthermore, the combination gemcitabine and carboplatin requires a shorter administration time as it does not require the hydration commonly administered prior to and following cisplatin. However, the combination gemcitabine and carboplatin can be expected to be associated with more myelotoxicity especially thrombocytopenia. Additionally it can be expected that the combination gemcitabine and carboplatin will be associated with a higher incidence of hypersensitivity reactions than the combination gemcitabine and cisplatin. As most patients with ovarian cancer over the last decade have been treated with Taxol and carboplatin as first-line chemotherapy and because the chance of hypersensitivity reactions to carboplatin increases as the number of cycles of carboplatin increases, ${ }^{[27]}$ it possible that a significant number of patients with recurrent ovarian cancer might develop hypersensitivity reactions to carboplatin when it is used as a salvage regimen in combination with gemcitabine.

Treatment of women with platinum-resistant ovarian cancer is very challenging as there are only a limited number of agents that could be effective among these women and the response to chemotherapy is not durable. ${ }^{[5-7]} \mathrm{We}$ found a significantly higher response rate among women with recurrent platinum-sensitive compared with women with platinum-resistant tumors (69.6\% vs. $20 \%, P=.024)$. Two previous ${ }^{[16,17]}$ studies of the combination of gemcitabine and platinum included women with both platinum-sensitive and platinum-resistant tumors. Our findings were similar to those reported by Nagourney et al. ${ }^{[17]}$ and Villella et al. ${ }^{[16]}$ who found higher response rates among women with platinumsensitive compared to those with platinum-resistant tumors ( $84 \%$ vs. $57 \%$ and $80 \%$ vs. $42 \%$, respectively). The response 
rate of patients with platinum-resistant tumors reported in our study (20\%) was slightly higher than the $16 \%$ response rate reported in a recent GOG study ${ }^{[21]}$ in a similar patient population. Markman et al. ${ }^{[28]}$ reported a similar response rate $(16 \%)$ using single agent gemcitabine among a group of women with platinum-paclitaxel refractory ovarian cancer. The findings reported by Markman et al. ${ }^{[28]}$ cast doubt on the significance of adding cisplatin among this group of patients. However, higher response rates $(42.9 \%-64 \%)$ to the combination gemcitabine and platinum among women with platinum-resistant ovarian cancer have been reported by other investigators. ${ }^{[15,19]}$ This combination adds to our rather limited armamentarium when treating women with this condition.

Limitations of the current study include its retrospective nature and inherent bias of retrospective studies including selection bias, relatively small number of patients and small number of patients with none serous histology limiting analysis to these types of tumors.

\section{CONFlicts OF InTEREST Disclosure}

The authors declare that there is no conflict of interest statement.

\section{REFERENCES}

[1] Parmer MK, Ledermann JA, Colombo N, et al. Paclitaxel plus platinum-based chemotherapy versus conventional platinum-based chemotherapy in women with relapsed ovarian cancer: the IOC4/AGO-OVAR-2.2 trial. Lancet. 2003; 361: 2099-106. http: //dx.doi.org/10.1016/S0140-6736(03) 13718-X

[2] Pfisterer J, Plante M, Vergote I, et al. Gemcitabine plus carboplatin compared with carboplatin in patients with platinum-sensitive recurrent ovarian cancer: an intergroup trial of the AGO-OVAR, the NCIC CTG, and the EORTC GCG. J Clin Oncol. 2006; 24: 4699707. PMid:16966687. http://dx.doi .org/10.1200/JC0. 2006. 06.0913

[3] Gershenson DM, Kavanagh JJ, Copeland LJ, et al. Re-treatment of patients with recurrent epithelial ovarian cancer with cisplatin-based chemotherapy. Obstet Gynecol. 1989; 73: 798-802. PMid:2704508.

[4] Markman M, Rothman R, Hakes T, et al. Second-line platinum therapy in patients with ovarian cancer previously treated with cisplatin. J Clin Oncol. 1991; 9: 389-93. PMid:1999708.

[5] Trimble EL, Adams JD, Vena D, et al. Paclitaxel for platinumrefractory ovarian cancer: results from the first 1,000 patients registered to National Cancer Institute Treatment Referral Center 9103. J Clin Oncol. 1993; 11: 2405-10. PMid:7902426.

[6] Gordon AN, Tonda M, Sun S, et al. Long-term survival advantage for women treated with pegylated liposomal doxorubicin compared with topotecan in a Phase 3 randomized study of recurrent and refractory epithelial ovarian cancer. Gynecol Oncol. 2004; 95: 1-8. PMid:15385103. http://dx.doi.org/10.1016/j.ygyno.2 004.07 .011

[7] ten Bokkkel Huinink W, Gore M, Carmichael J, et al. Topotecan versus paclitaxel for the treatment of recurrent epithelial ovarian cancer. J Clin Oncol. 1997; 15: 2183-93. PMid:2312855.

[8] Johnson SW, Ozols RF, Hamilton TC. Mechanisms of drug resistance in ovarian cancer. Cancer. 1993; 71(2 Suppl): 644-9. http: //dx.doi.org/10.1002/cncr.2820710224

[9] du Bois A, Belau A, Wagner U, et al. A phase II study of paclitaxel, carboplatin, and gemcitabine in previously untreated patients with epithelial ovarian cancer FIGO stage IC-IV (AGO-OVAR protocol OVAR-8). Gynecol Oncol. 2005; 96(2): 444-51. PMid:15661234. http://dx.doi.org/10.1016/j.ygyno.2004.10.020

[10] Lund B, Hansen OP, Theilade K, et al. Phase II study of Gemcitabine (2', 2'- difluorodeoxycycline) in previously treated ovarian cancer patients. J Natl Cancer Inst. 1994; 86: 1530-3. PMid:7932808. http://dx.doi.org/10.1093/jnci/86.20.1530
[11] Moufarji MA, Phillips DR, Cullinane C. Gemcitabine potentiates cisplatin cytotoxicity and inhibits repair of cisplatin-DNA damage in ovarian cancer cell lines. Mol Pharmacol. 2003; 63(4): 862-9. http://dx.doi.org/10.1124/mol.63.4.862

[12] van Moorsel CJ, Pinedo HM, Veerman G, et al. Mechanism of synergism between cisplatin and gemcitabine in ovarian and nonsmall-cell lung cancer cell lines. Br J Cancer. 1999; 80(7): 98190. PMid:10362105. http://dx.doi.org/10.1038/sj.bjc.66 90452

[13] Belpomme D, Krakowski I, Beaudin M, et al. Gemcitabine combined with cisplatin as first-line treatment in patients with epithelial ovarian cancer: a phase II study. Gynecol Oncol. 2003; 91(1): 32-8. http://dx.doi.org/10.1016/S0090-8258(03)00413-X

[14] Bauknecht T, Hefti A, Morack G, et al. Gemcitabine combined with cisplatin as first-line treatment in patients 60 years or older with epithelial ovarian cancer: a phase II study. Int J Gynecol Cancer. 2005; 15(1): 180-1.

[15] Rose PG, Mossburger K, Fusco N, et al. Gemcitabine reverses cisplatin resistance: demonstration of activity in platinum- and multidrug resistant ovarian and peritoneal carcinoma. Gynecol oncol. 2003; 88: 17-21. PMid:12504621. http://dx.doi.org/10.1006/gyn 0.2002 .6850

[16] Villella J, Marchetti D, Odunsi K, et al. Response of combination platinum and gemcitabine chemotherapy for recurrent epithelial ovarian carcinoma. Gynecol Oncol. 2004; 95: 539-545. PMid:15581960. http://dx.doi.org/10.1016/j.ygyno.2004.07.056

[17] Nagourney RA, Brewer CA, Radecki S, et al. Phase II trial of gemcitabine plus cisplatin repeating doublets therapy in previously treated, relapsed ovarian cancer patients. Gynecol Oncol. 2003; 88: 35-9. PMid:12504624. http://dx.doi.org/10.1006/gyno.20 02.6855

[18] Papadimitriou CA, Fountzilas G, Aravantinos G, et al. Secondline chemotherapy with gemcitabine and carboplatin in paclitaxelpretreated, platinum-sensitive ovarian cancer patients. A Hellenic Cooperative Oncology Group study. Gynecol Oncol. 2004; 92: 1529. PMid:14751151. http://dx.doi.org/10.1016/j.ygyno.2 003.09 .021

[19] Tewari D, Monk BJ, Hunter M, et al. Gemcitabine and cisplatin chemotherapy is an active combination in the treatment of platinumresistant ovarian and peritoneal carcinoma. Invest New Drugs. 2004; 22(4): 475-80. PMid:15292718. http://dx.doi.org/10.1023 /B:DRUG.0000036690.14585.a3 
[20] Kose MF, Sufliarsky J, Beslija S, et al. A phase II study of gemcitabine plus carboplatin in platinum-sensitive recurrent ovarian carcinoma. Gynecol Oncol. 2005; 96: 374-80. PMid:15661224. http://dx.doi.org/10.1016/j.ygyno.2004.10.011

[21] Brewer CA, Blessing JA, Nagourney RA, et al. Cisplatin plus gemcitabine in platinum-refractory ovarian or primary peritoneal cancer: A phase II study of the Gynecologic Oncology Group. Gynecol Oncol. 2006; 103: 446-50. PMid:16643994. http://dx.doi.org/10.10 $16 / j \cdot$ ygyno. 2006.03 .018

[22] du Bois A, Luck HJ, Pfisterer J, et al. Second-line carboplatin and gemcitabine in platinum sensitive ovarian cancer- a dose-finding study by the Arbeitsgemeinschaft Gynakologische Onkologie (AGO) Ovarian Cancer Study Group. Ann Oncol. 2001; 12: 1115-20. PMid:11583193. http://dx.doi.org/10.1023/A: 1011605008 922

[23] Kroep JR, Peters GJ, van Moorsel CJ, et al. Gemcitabine-cisplatin: a schedule finding study. Ann Oncol. 1999; 10(12): 1503-10. PMid:10643544. http://dx.doi.org/10.1023/A:1008339425 708

[24] World Health Organization Handbook for Reporting Results of Cancer Treatment. WHO Offset Publication No. 48, WHO, Geneva, 1979.

[25] Rustin GJ, Nelstrop AE, McClean P, et al. Defining response of ovarian carcinoma to initial chemotherapy according to serum CA-125. J
Clin Oncol. 1996; 14: 1545-51. PMid:8622070.

[26] Kyrgiou M, Salanti G, Pavlidis N, et al. Survival benefits with diverse chemotherapy regimens for ovarian cancer: a meta-analysis of multiple treatments. J Natl Cancer Inst. 2006; 98(22): 1655-63. PMid:17105988. http://dx.doi.org/10.1093/jnci/djj443

[27] Markman M, Kennedy A, Webster K, et al. Clinical features of hypersensitivity reactions to carboplatin. J Clin Oncol. 1999; 17(4): 1141. PMid:10561172.

[28] Markman M, Webster K, Zanotti K, et al. Phase 2 trial of singleagent gemcitabine in platinum-paclitaxel refractory ovarian cancer Gynecol Oncol. 2003; 593-6. http://dx.doi .org/10.1016/S00 90-8258 (03) 00399-8

[29] Bozas G, Bamias A, Koutsoukou V, et al. Biweekly gemcitqbine and cisplatin in platinum- resistant/refractory, paclitaxel-pre-treated ovarian and peritoneal carcinoma. Gynecol Oncol. 2007; 104: 5805. PMid:17052747. http://dx.doi.org/10.1016/j.ygyno.2 006.09 .006

[30] Sufliarsky J, Covanec J, Svetlovska D, et al. Neoplasma. 2009; 56 : 291-7. PMid:19473054. http://dx.doi.org/10.4149/neo_200 9_04_291

[31] Richardson DL, Backes FJ, Seaman LG, et al. Combination gencitabine, platinum and bevacizumab for the treatment of recurrent ovarian cancer. Gynecol Oncol. 2008; 111: 461-6. PMid:18829088. http://dx.doi.org/10.1016/j.ygyno.2008.08.011 